\title{
What mathematics teachers do and know: looks from inside and outside of the classroom to the mathematic-specificity of teacher work
}

\author{
Salvador Llinares ${ }^{1}$ (D)
}

Published online: 3 May 2019

(c) Springer Nature B.V. 2019

The four articles of this issue underline the need of mathematics-specific research approaches to mathematics teaching to improve both mathematics teacher education and mathematics teaching. These articles focus on how teachers can extend students' mathematical thinking, highlighting the role played by the teacher's knowledge during a specific mathematical work in teaching. They put our attention on the mathematical work-specific preparation for the teacher. Furthermore, these articles focus on core practices for teacher training (including prospective and practicing teachers). Aaron and Herbst focus on teachers' perspectives related to the activities of conjecturing and proving in high school geometry teaching (USA). Takker and Subramaniam centred on the knowledge demand for the teacher in teaching decimal fractions in Grade 6 (India). Miyakawa and Winsløw underline the organizational conditions that allow the link between what teachers do (inside and outside the classroom) and the professional knowledge they develop and share about their practices (Japan). Finally, Tirosh, Tsamir, Levenson, Barkai, and Tabach focus on preschool teacher knowledge of pattern structure in activities of exploring repeating patterns (Israel). In the four cases, there is a connection between the mathematics teaching and the teacher education assuming the mathematics teaching as a practice with a specific mathematical demand.

The articles come from four different countries and different cultural contexts (USA, India, Japan, and Israel). They consider different school levels (high school, primary school, secondary school, and preschool) and focus on different mathematical processes and topics (conjecturing and proving in geometry, the influence of whole numbers place value knowledge to understand decimal numbers; the introduction of linear equations; and the pattern structures in activities of exploring repeating patterns). However, the four articles share that the effectiveness of mathematics teaching depends on what teachers know and how teachers use the available resources (task, discourse, etc.) to respond to mathematics-specific demand of teaching. Using resources effectively depends on the teachers' mathematics-specific knowledge in each situation and on the organizational contexts in which they work. Specific mathematical knowledge means the different dimensions

Salvador Llinares

sllinares@ua.es

1 Departamento de Innovación y Formación Didáctica, Didáctica de la Matemática, Facultad de Educación, Universidad de Alicante, Campus de Sant Vicent del Raspeig, 03080 Alacant, Spain 
through which we can approach to the relationships between the mathematics teaching practice and the teacher's knowledge (Chapman 2013; Llinares 2018). In particular, attending to the specifics of mathematical aspects in teaching can help to improve students' mathematics learning through the teacher's practice. What teachers need to know and do to manage the mathematics teaching is emphasized.

Aaron and Herbst focus on teachers' perspectives that justify the existence of distinct activity structures organizing the classroom interaction regarding the activities of conjecturing and proving in high school. They articulate their approaches through the notion of instructional situation. Adopting three perspectives (teachers' perspective of students' work, students' capabilities for conjecturing and proving and the nature of work done by mathematicians), they analyse how practicing teachers, in focus groups, talk on and justify as distinct the instructional situations of making conjectures and doing proofs. The animated scenario used is designed to create the context that facilitates the reactions of teachers on what is common or not in geometry instruction. The instructional situation was formed by three segments: pose a problem that implies looking for statements that could be proved; discuss and refine conjectures; and prove a student's conjecture. Aaron and Herbst analyse the reasons that practicing teachers provided during the several focus group sessions, when they separated the activities of conjecturing and proving and how they valued the instructional situations that present together these two activities. Their findings allow to understand the teachers' reasons to separate the conjecturing and proving activities in specific contextual condition (the need to present the proof in the two-column format in the US context). These findings underline the relevance of specific mathematical practice of teachers, particularly, in managing a clear transition between the activities of conjecturing and proving in geometry instruction.

Takker and Subramaniam' article centres on the mathematical knowledge demand when a teacher responds to students' thinking during the teaching of decimal numbers. The aim is to unpacked teachers' knowledge involved in the classroom setting that allows teachers to convert some classroom incidents into learning opportunities. Changes in the way in which a teacher listen to their students and manage the specific mathematics incidents in a classroom during a period of 2 years are used to unpack the specific mathematical knowledge required to teach. Takker and Subramaniam conceptualize the notion of knowledge demand as "mathematical challenges faced by a teacher while teaching a specific topic". With this particular point of view, the context of education reform in which a teacher is making a transition from a more traditional to a student-centred instruction, is suitable in this research. The case study presented is supported by a great diversity of data collected during 2 years (observation, prior and post-lesson interviews and field-notes). The focus on the decimal numbers teaching in two consecutive years allows Takker and Subramaniam to identify the changes in the teacher's practice and unpack the specific mathematical demand engaged in responding to students' mathematical thinking effectively. The analysis of different classroom incidents with hypothetical alternatives shows the complexity of managing the mathematical knowledge demand. This type of analysis is what the authors consider that can feed teacher education courses.

Miyakawa and Winsløw argue the necessity of adopting a holistic approach regarding the cultural and institutional conditions in Japan to understand the process of developing and disseminating the mathematics teacher knowledge. They present, in two episodes, how the specific organizational conditions in which mathematics teachers work in Japan support the processes of building and disseminating specific mathematical knowledge for teaching. Both episodes are presented as examples of the teacher's work outside the classroom, particularly, when they prepare the teaching. The first episode involves a meeting in 
a teachers' association seminar where mathematics teachers discuss about an abstract of a research report related to the introduction of linear equations. The second episode focuses on the presentation and discussion of the full paper at a regional conference for mathematics teachers. Therefore, authors underline "ways in which 'local knowledge' becomes more widely shared" by "an infrastructure for professional exchange that goes far beyond the 'real time' observation and discussion of lessons". In this case, the theoretical approach adopted is the anthropological theory of didactic (ATD) that allows to make visible the network of institutional levels through which mathematics teacher knowledge is developed and disseminated. In the authors' words 'the school-based activity can lead to professional knowledge about mathematics teaching which is public, storable, shareable, verifiable and improvable". Through the description and analysis of the two episodes, Miyakawa and Winsløw show how the institutional conditions support the way in which specific didactical and mathematical "praxeologies" are built and disseminated. Two aspects are underlined: the role played by the discussion with other teachers of the materials produced by the teachers themselves, and the specific focus on the mathematical details of the tasks that can engage students with.

Finally, Dina Tirosh and her colleagues provide preschool teachers with a professional development to promote their knowledge of pattern structure for teaching patterning. The professional development has two objectives: producing solutions, strategies, and explanations, and evaluating given solutions, strategies, and explanations. In this article, the focus is on the mathematics-specific knowledge that preschool teachers should know to teach patterns activities more mathematically focused (e.g. types of structure, the recognition of the unit or the repeating patterns). The type of tasks used can be considered as suggestions to other professional development courses that have the goal of developing in preschool teachers a specific mathematical knowledge regarding the patterning activities and the language involved.

In the four articles, the connection of research on mathematics teaching and on teacher learning is made considering how teacher educators identify the specific mathematics knowledge that teachers (or prospective teachers) need to know to answer the demands of mathematics teaching. Although the four approaches are framed by different activities (professional development initiatives in Aaron and Herbst, Miyakawa and Winsløw, and Tirosh and colleagues; and the analysis of the practice of a mathematics teacher in transition in Takker and Subramaniam), all of them try to connect what teachers do and know inside and outside of classroom to the mathematics-specific demand in mathematics teaching. Furthermore, this connection informs about the content in teacher education and focuses our attention on the organizational contexts in which teachers work.

These articles are examples of how teacher educators attempt to generate a deeper understanding of mathematics teaching and teacher's knowledge using theoretical frameworks to describe mathematics teaching and teachers' learning. The theoretical approaches adopted in each of them underline the complexity of the situations studied: the notions of instructional situation and mathematics-specific work (Aaron and Herbst); the mathematical demand (Takker and Subramaniam); the anthropological theory of the didactics to analyse the network of institutional levels where the mathematics teacher knowledge is developed and disseminated (Miyakawa and Winsløw); and cognitive approaches to unravel the mathematical-specific features of prospective teachers' knowledge (Tirosh and colleagues). However, they have a common factor in their background: the understanding of the mathematical specificity of how teachers establish relationships with students' mathematical learning and how this new knowledge might be useful in mathematics teacher education. In some sense, these four articles provide us with knowledge to support opportunities that can 
rehearse and develop components of practice (pedagogies of enactment) (Grossman and McDonald 2008) in mathematics teacher education. For example, knowledge about what type of feedback prospective and mathematics teachers should receive from mathematics teacher educators when they are involved in activities such as: blending the activities of conjecturing and proving, responding to the mathematical demand of decimal number teaching in primary school or the mathematical demand of the structure patterns teaching in preschool, or sharing with other colleagues and disseminating their practice reports in different professional development initiatives (Morris and Hiebert 2011). In other words, these articles provide knowledge about mathematics teaching and institutional conditions that can inform mathematics teacher education.

\section{References}

Chapman, O. (2013). Investigating teachers' knowledge for teaching mathematics. Journal of Mathematics Teacher Education, 16(4), 237-243.

Grossman, P., \& McDonald, M. (2008). Back to the future: Directions for research in teaching and teacher education. American Educational Research Journal, 45(1), 184-205.

Llinares, S. (2018). Mathematics teachers' knowledge, knowledge-based reasoning, and contexts. Journal of Mathematics Teacher Education, 21(1), 1-3.

Morris, N., \& Hiebert, J. (2011). Creating shared instructional products: An alternative approach to improving teaching. Educational Researcher, 40(1), 5-14.

Publisher's Note Springer Nature remains neutral with regard to jurisdictional claims in published maps and institutional affiliations. 